\title{
The suppressive effect of a commercial extract from Durvillaea potatorum and Ascophyllum nodosum on infection of broccoli by Plasmodiophora brassicae
}

\author{
D. Wite ${ }^{1} \cdot$ S. W. Mattner ${ }^{1,2,3} \cdot$ I. J. Porter ${ }^{1,3} \cdot$ T. Arioli $^{4}$
}

Received: 26 July 2014 / Revised and accepted: 6 March 2015 / Published online: 21 March 2015

(C) The Author(s) 2015. This article is published with open access at Springerlink.com

\begin{abstract}
A sand solution technique demonstrated the capacity for a commercial seaweed extract from Durvillaea potatorum and Ascophyllum nodosum (Seasol Commercial ${ }^{\mathbb{R}}$ ) to significantly suppress infection of broccoli by Plasmodiophora brassicae. In the primary stages of infection, the extract reduced the number of plasmodia formed in the root hairs by $55 \%$. Later, in the secondary stages of infection, the extract reduced plasmodia in the root cortical cells by up to $84 \%$. The suppression of infection was found to be independent of the dilution of the extract applied (1:25 and 1:500). The basis for these results is unlikely to be a nutrient or $\mathrm{pH}$ effect since the extract had little impact on these parameters, particularly at the lower dilution (1:200). Rather, we hypothesise that the suppression of infection by the seaweed extract was due to its stimulation of resistance mechanisms in the host, which is possibly related to laminarins in the extract and/or the effect of exogenous growth regulators or undiscovered molecules in the extract disrupting the infection process.
\end{abstract}

Keywords Clubroot · Kelp extract · Seaweed extract . Seasol ${ }^{\circledR}$

S. W. Mattner

swmattner@hotmail.com

1 Department of Environment and Primary Industries, Knoxfield, Victoria, Australia

2 Victorian Strawberry Industry Certification Authority, Toolangi, Victoria, Australia

3 School of Botany, La Trobe University, Bundoora, Victoria, Australia

4 Seasol International, Bayswater, Victoria, Australia

\section{Introduction}

Clubroot caused by the obligate soil-borne parasite Plasmodiophora brassicae is considered the most important soil-borne disease of brassica crops, such as broccoli, cabbage, canola and others (Dixon 2014; Donald and Porter 2009; Donald and Porter 2014). The pathology of clubroot infection consists of several phases - primary phases that occur in the root hair and secondary phases that occur in the cortex. An amoeboid form of the pathogen may link the phases of infection (Donald et al. 2008). Ultimately, infection can result in abnormal tissue proliferation in the host and the formation of root galls, which are characteristic of the disease.

Changes in auxin and cytokinin metabolism are thought to be key mechanisms in the development and formation of clubroot galls (Devos et al. 2005; Siemens et al. 2006). Compared with healthy plants, concentrations of indole-3-acetic acid (IAA) or conjugated IAA in infected roots alternate from higher to lower levels (Kavanagh and Williams 1981; Ludwig-Müller et al. 1993; Devos et al. 2005), with the transition possibly correlating with the change from primary to secondary phases of infection (Devos et al. 2005). By comparison, most authors report increased cytokinin activity in infected compared with healthy plants (Dekhuijzen and Overeem 1971; Dekhuijzen 1980), with Müller and Hilgenberg (1986) showing that plasmodia of P. brassicae can synthesise the cytokinin, trans-zeatin. However, Devos et al. (2005) found that infection reduced the total active cytokinin content of root tissue and hypothesised that plasmodia of $P$. brassicae act as a sink for zeatin in the primary infection phases. In Arabidopsis thaliana, Siemens et al. (2006) found that genes involved in auxin homeostasis were upregulated whereas those involved in cytokinin homeostasis were downregulated during the infection process. Despite the potential role of auxins and cytokinins in the formation of clubroot 
galls, there are few studies on the effects of exogenous applications of these and other growth regulators on pathogenesis, especially when they are applied in seaweed extracts.

It is well documented that seaweed extracts can improve crop health when applied as soil amendments or foliar treatments in horticultural systems (Khan et al. 2009, Craigie 2010, Arioli et al. 2015). For example, Mattner et al. (2013) showed that a commercial extract from the brown algae Durvillaea potatorum and Ascophyllum nodosum reduced the incidence of white blister, caused by Albugo candida, in the establishment of broccoli seedlings by $23 \%$. Seaweed extracts can affect soil-borne diseases through a direct suppressive effect on pathogens and pathogenicity (Mattner et al. 2014) or through stimulation of antagonistic microflora in treated soil (Dixon and Walsh 2004). Most evidence, however, suggests that seaweed extracts or their components, such as laminarins, can stimulate resistance mechanisms in the host against pathogen infection (Aziz et al. 2003, Jayaraj et al. 2008, Jayaraman et al. 2010, Subramanian et al. 2011). Moreover, growth regulators contained in seaweed extracts, including auxins, cytokinins and betaines, have the potential to further moderate these resistance mechanisms (Kazan and Manners 2009; Naseem and Dandekar 2012).

In Australia, a significant number of brassica growers have applied seaweed extracts as components of their management strategies for clubroot. Despite this, few scientific studies report on the effects of seaweed extracts on infection of brassicas by $P$. brassicae or on clubroot. In pot trials, Stewart (2008) found that soil amendment with two commercial seaweed products derived from Ascophyllum nodosum, a Laminaria sp. and a Sargassum sp. reduced the disease severity of clubroot by up to $33 \%$, although this was not significant at the $p \leq 0.05$ level. When considering the activity of commercial seaweed extracts on plant health, it is important to recognise that their effects and properties may differ due to the species of seaweed utilised and the commercial extraction systems employed in their production (Verkleij 1992). Our study used a sand solution technique to test the hypothesis that a commercial seaweed extract from $D$. potatorum and A. nodosum can reduce infection of broccoli by P. brassicae.

\section{Method}

\section{Sand solution technique}

The sand solution technique used in this experiment is described by Donald and Porter (2004) and is an established method to observe infection of brassicas by P. brassicae. In this technique, acid-washed, coarse sand (Banksia Nurseries, Knoxfield, Australia) was autoclaved $\left(121^{\circ} \mathrm{C} / 100 \mathrm{kPa}\right)$ and loosely packed into $5-\mathrm{mL}$ tapered pipette tubes (Oxford Labware, USA). Broccoli seed (cv. Marathon, Henderson
Seeds, Templestowe Lower, Australia) was surface-sterilised for $3 \mathrm{~min}$ in a $70 \%$ ethanol $/ 10 \%$ sodium hypochlorite solution, followed by three rinses in sterile distilled water, and dried in a laminar flow cabinet overnight on sterile filter paper. A single seed was sown into the sand in each of the pipette tubes. Two tubes were placed inside a larger 50-mL Falcon tube containing a buffered nutrient solution (MES Solution, USA). This nutrient solution was developed by Myers and Campbell (1985) to maximise P. brassicae infection, without causing nutrient stress in the host, and consists of the following: $\mathrm{MgSO}_{4}(1 \mathrm{mM}), \mathrm{KNO}_{3}(2.5 \mathrm{mM}), \mathrm{Ca}\left(\mathrm{NO}_{3}\right)_{2}(2.5 \mathrm{mM})$, $\mathrm{KH}_{2} \mathrm{PO}_{4}(0.5 \mathrm{mM}), \mathrm{H}_{3} \mathrm{BO}_{3}(92 \mu \mathrm{M}), \mathrm{MnCl}_{3}(18 \mu \mathrm{M}), \mathrm{CuSO}_{4}$ $(0.64 \mu \mathrm{M}), \mathrm{H}_{2} \mathrm{Mo}_{2} \mathrm{O}_{4}(0.14 \mu \mathrm{M}), \mathrm{ZnSO}_{4}(1.5 \mu \mathrm{M})$ and $\mathrm{Fe}$ EDTA $(1.3 \mu \mathrm{M})$. At 5 days after sowing, $2 \mathrm{~mL}$ of seaweed extract (1:25 or 1:200 dilutions, see below) or sterile distilled water for the control were applied to the sand within the pipette tubes. At 28 days after sowing, stored $\left(-20^{\circ} \mathrm{C}\right)$ spore suspensions of $P$. brassicae collected from infected broccoli plants in Werribee South, Victoria, Australia (ECD code 16/ 19/31), were thawed and resuspended in sterile distilled water to contain a concentration of $10^{6}$ spores $\mathrm{mL}^{-1}$, using a haemocytometer. Plants in the pipette tubes were inoculated by applying $0.2 \mathrm{~mL}$ of the spore suspension to the sand. Seedlings were kept in a growth cabinet $\left(25^{\circ} \mathrm{C}\right.$ day, $20^{\circ} \mathrm{C}$ night, $90 \%$ relative humidity, $12-\mathrm{h}$ days) for the duration of the experiment, and nutrient/seaweed extract solutions replaced as required.

\section{Seaweed extract}

The seaweed extract used in the experiment was an alkaline hydrolysis product (Arioli et al. 2015) from D. potatorum and A. nodosum (Seasol Commercial ${ }^{\circledR}$, Seasol International, Bayswater, Australia), which was sterilised by exposure to $\mathrm{UV}$ for $2 \mathrm{~h}$ in a laminar flow cabinet. This method has previously sterilised small volumes $(15 \mathrm{~mL})$ of the extract without reducing its bioactivity (Mattner et al. 2014). The undiluted extract has a $\mathrm{pH}$ of 10.5 and contains $0.2 \%(w / v) \mathrm{N}, 0.02 \% \mathrm{P}$, $3.7 \% \mathrm{~K}, 0.3 \% \mathrm{~S}, 458 \mathrm{mg} \mathrm{L}^{-1} \mathrm{Ca}, 972 \mathrm{mg} \mathrm{L}^{-1} \mathrm{Mg}$, $115 \mathrm{mg} \mathrm{L}^{-1} \mathrm{Fe}, 2 \mathrm{mg} \mathrm{L}^{-1} \mathrm{Mn}, 15 \mathrm{mg} \mathrm{L}^{-1} \mathrm{~B}$, and $5 \mathrm{mg} \mathrm{L}^{-1}$ $\mathrm{Zn}$ (Seasol International 2015). In addition to low concentrations of nutrients, the undiluted extract contains $7 \%(w / v)$ total laminarins, $154 \mu \mathrm{g} \mathrm{L}^{-1}$ total auxins, $36 \mu \mathrm{g} \mathrm{L} \mathrm{L}^{-1}$ total cytokinins (including zeatin, dihydrozeatin, isopentenyl-adenine, and their corresponding ribosides and glucosides; Tay et al. 1985,1987 ) and $382 \mu \mathrm{g} \mathrm{L}^{-1}$ total betaines (Seasol International 2015). Total concentrations of nutrients and growth regulators in the sand solutions in the different treatments were determined based on these figures and the prepared concentrations of the buffered nutrient solution (see above). In addition, the $\mathrm{pH}$ of the sand solutions in the different treatments was measured using a $\mathrm{pH}$ meter. 


\section{Infection assessment}

Infection was assessed at 14, 28 and 45 days after inoculation (d.a.i.). At each assessment date, the roots of six plants per treatment (i.e. two replicate plants by three blocks) were harvested, rinsed free of sand, fixed with formyl acetic acid and then stained with FFA Phloxine B to allow observation of the development of infection by $P$. brassicae. Twenty root sections $(200 \mu \mathrm{m}$ long) per plant (i.e. 120 root sections in each treatment) were examined under compound microscope for the number of plasmodia in the root hairs and cortical cells.

\section{Trial design and treatments}

The experiment was conducted as a randomised complete block design, with three blocks. Each block contained six replicate plants of each treatment (i.e. a total of 18 plants per treatment). Two plants per treatment per block (i.e. six plants per treatment) were harvested at each of the three sampling dates (see above). Treatments included 1:25 (plus and minus inoculation) and 1:200 (plus inoculation) dilutions of seaweed extract, and sterile distilled water (plus and minus inoculation) as the control. Data were analysed by ANOVA using Genstat v. 12.1 (VSN International, UK). Homogeneity of variance was determined from plots of fitted values versus residuals, while histograms of residuals were examined for normality of distribution. Fisher's least significance difference test was used to identify significant differences between treatment means. The level of significance used was $p \leq 0.05$.

\section{Results}

Due to the low nutrient content of the undiluted seaweed extract and the dilutions used in this experiment, differences in the $\mathrm{pH}$ and nutrient content of the sand solutions in the different treatments were negligible, except for $\mathrm{K}$ and $\mathrm{Fe}$ (Table 1). In particular, the nutrient content between the control and the 1:200 seaweed extract treatment were similar. Unlike the seaweed extract treatments, however, the sand solution in the control contained no laminarins or growth regulators.

In the primary phases of infection, treatment with the seaweed extract reduced the number of plasmodia formed by P. brassicae in broccoli root hairs by up to $55 \%$ compared with the control (Table 2 ). The effect was statistically significant at 28 d.a.i., but not at 14 d.a.i. At 45 d.a.i., in the secondary phases of infection, plasmodia had formed in cortical cells and there were up to $84 \%$ fewer in the roots of plants in the seaweed extract treatments than in the control (Table 2). The dilution of seaweed extract (1:25 or 1:200) had no significant effect on the numbers of plasmodia formed by P. brassicae in root hairs or cortical cells of broccoli. No plasmodia formed in the non-inoculated treatments.
Table 1 Calculated concentration of elements and compounds in the sand solutions of different seaweed extract (SE) treatments

\begin{tabular}{llll}
\hline Component & Control & SE (1:25) & SE (1:200) \\
\hline $\mathrm{pH}$ & 5.73 & 6.14 & 5.79 \\
$\mathrm{~N}\left(\mathrm{mg} \mathrm{L}^{-1}\right)$ & 97.3 & 103.2 & 98.0 \\
$\mathrm{P}\left(\mathrm{mg} \mathrm{L}^{-1}\right)$ & 14.3 & 14.9 & 14.4 \\
$\mathrm{~K}\left(\mathrm{mg} \mathrm{L}^{-1}\right)$ & 108.6 & 218.2 & 122.3 \\
$\mathrm{~S}\left(\mathrm{mg} \mathrm{L}^{-1}\right)$ & 29.7 & 38.6 & 30.9 \\
$\mathrm{Ca}\left(\mathrm{mg} \mathrm{L}^{-1}\right)$ & 92.7 & 94.1 & 92.9 \\
$\mathrm{Mg}\left(\mathrm{mg} \mathrm{L}^{-1}\right)$ & 22.5 & 25.4 & 22.9 \\
$\mathrm{Fe}\left(\mu \mathrm{g} \mathrm{L}^{-1}\right)$ & 67.2 & 408.0 & 109.8 \\
$\mathrm{Mn}\left(\mu \mathrm{g} \mathrm{L}^{-1}\right)$ & 915.6 & 921.5 & 916.4 \\
$\mathrm{~B}\left(\mu \mathrm{g} \mathrm{L}^{-1}\right)$ & 920.9 & 965.4 & 926.5 \\
$\mathrm{Zn}\left(\mu \mathrm{g} \mathrm{L}^{-1}\right)$ & 90.8 & 105.6 & 92.7 \\
$\mathrm{Mo}\left(\mu \mathrm{g} \mathrm{L}^{-1}\right)$ & 24.9 & 24.9 & 24.9 \\
$\mathrm{Cu}\left(\mu \mathrm{g} \mathrm{L}^{-1}\right)$ & 37.6 & 37.6 & 37.6 \\
Laminarins $\left(\mathrm{mg} \mathrm{L}^{-1}\right)$ & 0.0 & 207.4 & 25.9 \\
Auxins $\left.(\mu \mathrm{g} \mathrm{L})^{-1}\right)$ & 0.00 & 0.45 & 0.06 \\
Cytokinins $\left(\mu \mathrm{g} \mathrm{L}^{-1}\right)$ & 0.00 & 0.11 & $1.3 \times 10^{-2}$ \\
Betaines $\left(\mu \mathrm{g} \mathrm{L}^{-1}\right)$ & 0.00 & 1.13 & 0.14 \\
\hline
\end{tabular}

\section{Discussion}

To our knowledge, this is the first published report of a commercial seaweed extract directly suppressing infection of broccoli by $P$. brassicae. In this study, suppression of infection was observed as fewer numbers of plasmodia in the roots of the host. The seaweed extract had a greater effect in suppressing the secondary phases of infection (plasmodia in the root cortex were reduced by up to $84 \%$ ) than the primary phases of infection (plasmodia in the root hairs were reduced by up to $55 \%$ ). The underlying biological reasons for this difference,

Table 2 Number of plasmodia (per $200 \mu$ m length of root section) in the root hairs and cortical cells of broccoli following treatment with a seaweed extract (SE) and inoculation with Plasmodiophora brassicae

\begin{tabular}{|c|c|c|c|}
\hline \multirow[t]{2}{*}{ Treatment } & \multicolumn{2}{|c|}{$\begin{array}{l}\text { Plasmodia in } \\
\text { the root hair }\end{array}$} & \multirow{2}{*}{$\begin{array}{l}\text { Plasmodia in } \\
\text { cortical cells } \\
45 \text { d.a.i. }\end{array}$} \\
\hline & 14 d.a.i. & 28 d.a.i. & \\
\hline \multicolumn{4}{|l|}{ Inoculated } \\
\hline SE $(1: 25)$ & 2.1 & 1.3 & 16.4 \\
\hline SE $(1: 200)$ & 2.1 & 1.2 & 8.1 \\
\hline Control (water) & 3.0 & 2.7 & 51.7 \\
\hline \multicolumn{4}{|l|}{ Non-inoculated } \\
\hline SE $(1: 25)$ & 0.0 & 0.0 & 0.0 \\
\hline Control (water) & 0.0 & 0.0 & 0.0 \\
\hline $\operatorname{LSD}(p=0.05)$ & 1.7 & 0.6 & 8.9 \\
\hline
\end{tabular}

$L S D$ least significant difference where $p=0.05$, d.a.i. days after inoculation 
however, could not be determined by the current study and warrant further investigation. It is possible that the extracts slowed the development of infection, or they interfered with transition from the primary to secondary phases of infection.

It is important to recognise that suppression of infection does not always translate to reduced clubroot severity or improved commercial yields of broccoli. Despite this, our unpublished field and glasshouse research conducted under conditions of low disease expression showed a trend towards reduced clubroot severity and gall sizes in broccoli treated with the seaweed extract. Similarly, Stewart (2008) found a trend towards reduced clubroot severity in broccoli plants treated with a different seaweed extract from $A$. nodosum, although this was not significant at the $p \leq 0.05$ level. Further field and glasshouse trials conducted under higher disease pressures are needed to determine if the effect of the seaweed extract in suppressing infection of broccoli by $P$. brassicae translates to lower clubroot severity.

Infection of brassicas by $P$. brassicae is strongly influenced by $\mathrm{pH}$, with infection increasing under acidic conditions (Donald and Porter 2004, 2009). Using the identical sand solution method as the current experiment, Donald and Porter (2004) found that raising the $\mathrm{pH}$ of the nutrient solution from 5.5 to 8.0 reduced the proportion of root hairs of broccoli infected by $P$. brassicae by $70 \%$. In contrast, raising the $\mathrm{pH}$ of the nutrient solution from 5.5 to 6.5 only reduced infection by $5 \%$. In the current experiment, the addition of seaweed extract at dilutions of 1:25 and 1:200 raised the $\mathrm{pH}$ of the nutrient solution-from pH 5.73 to 6.14 and 5.79, respectively. Given that both dilutions of seaweed extract inhibited $P$. brassicae infection to an equivalent level and the comparative results of Donald and Porter (2004), there is little evidence that the effect in the current trial was due to $\mathrm{pH}$. Nonetheless, the use of alkaline seaweed extracts to modify $\mathrm{pH}$ in the rhizosphere of brassica crops warrants further investigation as a possible component in clubroot management.

Infection of brassicas by $P$. brassicae is also influenced by some nutrients (Donald and Porter, 2009). For example, increased levels of Ca (Donald and Porter 2004), Mg (Myers and Campbell 1985), and B (Webster and Dixon 1991) have the capacity to decrease infection. The nutrient content of the sand solution in the current trial was sufficient to prevent nutrient stress in the host plant but allow maximum expression of infection (Myers and Campbell 1985). Due to the dilutions used and their relatively low nutrient content, the addition of the seaweed extract treatments to plants in the experiment did not markedly affect nutrient concentrations in the sand solution (Table 1), except for increased levels of Fe and $\mathrm{K} . \mathrm{Fe}$ is not noted to affect infection of brassicas by $P$. brassicae (Donald and Porter 2009), while increased levels of $\mathrm{K}$ can enhance infection rather than suppress it (Prabhu et al. 2007). This in addition to the fact that dilution of the seaweed extract did not affect its ability to suppress infection, suggesting that a direct nutrient effect from the extracts in reducing infection is highly unlikely.

Previous research has shown that the undiluted seaweed extract used in the current study can have a direct suppressive effect on the survival and growth of some pathogens (e.g. Sclerotinia minor) or on their pathogenicity (Mattner et al. 2014). By comparison, the extracts used in the current studies were diluted, so a direct biocidal effect against zoospores of $P$. brassicae seems unlikely. Moreover, there was no difference in the ability of high and low dilutions of the extract to suppress infection. Rather, it is hypothesised that the suppression of infection by the seaweed extract was due to its stimulation of resistance mechanisms in the host and/ or the effect of exogenous growth regulators or other undiscovered molecules in the extract disrupting the infection process.

It is well established that some elicitors (e.g. salicylic acid) can increase the expression of resistance genes and nanomolar concentrations of defence compounds in Arabidopsis thaliana challenged by P. brassicae (Agarwal et al. 2011; Lovelock et al. 2013). Other experiments have detected similar gene responses in Arabidopsi thaliana treated with seaweed extracts from Ascophyllum nodosum (Jayaraj et al. 2008; Jayaraman et al. 2010). Similarly, laminarins contained in various seaweed extracts can elicit defence responses in plants (Klarzynski et al. 2000; Aziz et al. 2003). It is possible that the ability of the seaweed extract to reduce infection of broccoli by $P$. brassicae in the current study was due to a similar effect, since the diluted extracts contained laminarins (Table 1). Gene expression experiments using the Arabidopsis thalianal $P$. brassicae system are needed to test this hypothesis.

Even though cytokinins and auxins play an important role in the development of clubroot, few studies have tested the application of exogenous growth regulators on infection. Dekhuijzen and Overeem (1971) demonstrated that P. brassicae-infected and non-infected callus tissue of turnip required different concentrations of exogenous auxins and cytokinins to support their growth. Siemens et al. (2006) found that a cytokinin overexpressing line of Arabidopsis thaliana was resistant to clubroot disease. In contrast, Stewart (2008) postulated that application of exogenous cytokinins would increase disease severity in brassica crops by stimulating root hair formation, which is the primary site of infection for $P$. brassicae. Furthermore, Arioli et al. (2015) reported the presence of other growth regulators, i.e. strigolactones and brassinosteroids, in the seaweed extract investigated in the current trial. The effects of growth regulators on the interaction between plant development and pathogen infection are complex (Kazan and Manners 2009; Naseem and Dandekar, 2012). More chemical characterisation and investigation of complex seaweed extracts is needed to uncover the true mode of action for the seaweed extract we found to disrupt the infection process of $P$. brassicae in broccoli. 
Open Access This article is distributed under the terms of the Creative Commons Attribution License which permits any use, distribution, and reproduction in any medium, provided the original author(s) and the source are credited.

\section{References}

Agarwal A, Kaul V, Faggian R, Rookes JE, Ludwig-Müller J, Cahill DM (2011) Analysis of global host gene expression during the primary phase of the Arabidopsis thaliana-Plasmodiophora brassicae interaction. Funct Plant Biol 38:462-478

Arioli T, Mattner SW, Winberg PC (2015) Applications of seaweed extracts in Australian Agriculture: past, present and future. J Appl Phycol (submitted)

Aziz A, Poinssot B, Daire X, Adrian M, Bézier A, Lambert B, Joubert JM, Pugin A (2003) Laminarin elicits defense responses in grapevine and induces protection against Botrytis cinerea and Plasmopara viticola. Mol Plant Microbe Interact 16:118-1128

Craigie JS (2010) Seaweed extract stimuli in plant science and agriculture. J Appl Phycol 23:371-393

Dekhiujzen HM (1980) The occurrence of free and bound cytokinins in clubroots of Plasmodiophora brassicae infected turnip tissue cultures. Physiol Plant 49:169-176

Dekhiujzen HM, Overeem JC (1971) The role of cytokinins in clubroot formation. Physiol Plant Path 1:18-20

Devos S, Vissenberg K, Verbelen JP, Prinsen E (2005) Infection of Chinese cabbage by Plasmodiophora brassicae leads to a stimulation of plant growth: impacts on cell wall metabolism and hormone balance. New Phytol 166:241-250

Dixon GR (2014) Clubroot (Plasmodiopora brassicae Woronin) - an agricultural and biological challenge worldwide. Can J Plant Path 36:5-18

Dixon GR, Walsh UF (2004) Suppressing Pythium ultimum induced damping-off in cabbage seedlings by biostimulation with proprietary liquid seaweed extracts. Acta Hort 635:103-106

Donald EC, Porter IJ (2004) A sand-solution culture technique used to observe the effect of calcium and $\mathrm{pH}$ on root hair and cortical stages of infection by Plasmodiophora brassicae. Aust Plant Path 33:585589

Donald EC, Porter IJ (2009) Integrated control of clubroot. J Plant Growth Regul 28:212-228

Donald EC, Porter IJ (2014) Clubroot in Australia: the history and impact of Plasmodiophora brassicae in Brassica crops and research efforts directed towards its control. Can J Plant Path 36:66-84

Donald EC, Jaudzems G, Porter IJ (2008) Pathology of cortical invasion by Plasmodiophora brassicae in clubroot resistant and susceptible Brassica oleracea hosts. Plant Pathol 57:201-209

Jayaraj J, Wan A, Rahman M, Punja ZK (2008) Seaweed extract reduces foliar fungal diseases on carrot. Crop Prot 27:1360-1366

Jayaraman J, Norrie J, Punja ZK (2010) Commercial extract from the brown seaweed Ascophyllum nodosum reduces fungal diseases in greenhouse cucumber. J Appl Phycol 23:353-361

Kavanagh JA, Williams PH (1981) Indole auxins in Plasmodiophora infected cabbage roots and hypocotyls. Trans Brit Mycol Soc 77: $125-129$

Kazan K, Manners JM (2009) Linking development to defense: auxin in plant-pathogen interactions. Trends Plant Sci 14:373-382
Khan W, Rayirath UP, Subramanian S, Jithesh MN, Rayorath P, Hodges DM, Critchley AT, Craigie JS, Norrie J, Prithiviraj B (2009) Seaweed extracts as biostimulants of plant growth and development. J Plant Growth Regul 27:270-279

Klarzynski O, Plesse B, Joubert JM, Yvin JC, Kopp M, Kloareg B, Fritig B (2000) Linear $\beta-1,3$ glucans are elicitors of defense responses in tobacco. Plant Physiol 124:1027-1037

Lovelock DA, Donald EC, Conlan XA, Cahill DM (2013) Salicylic acid suppression of clubroot in broccoli (Brassica oleraceae var. italica) caused by the obligate biotroph Plasmodiophora brassicae. Aust Plant Pathol 42:141-153

Ludwig-Müller J, Bendel U, Thermann P, Ruppel M, Epstein E, Hilgenberg W (1993) Concentrations of indole-3-acetic acid in plants of tolerant and susceptible varieties of Chinese cabbage infected with Plasmodiophora brassicae Woron. New Phytol 125: 763-769

Mattner SW, Wite D, Riches DA, Porter IJ, Arioli T (2013) The effect of kelp extract on seedling establishment of broccoli on contrasting soil types in southern Victoria, Australia. Biol Agric Hortic 29:258-270

Mattner SW, Villalta ON, Wite D, Porter IJ, Arioli T (2014) In vitro suppression of Sclerotinia minor by a seaweed extract from Durvillaea potatorum and Ascophyllum nodosum. Aust Plant Dis Notes 9:137

Müller P, Hilgenberg W (1986) Isomers of zeatin and zeatinriboside in clubroot tissue: evidence for trans-zeatin biosynthesis by Plasmodiophora brassicae. Physiol Plant 66:245-250

Myers DF, Campbell RN (1985) Lime and the control of clubroot of crucifers: effects of $\mathrm{pH}$, calcium, magnesium and their interactions. Phytopath 75:670-673

Naseem M, Dandekar T (2012) The role of auxin-cytokinin antagonism in plant pathogen interactions. PLoS Pathog 8(11):e1003026

Prabhu AS, Fageria NK, Huber DM, Rodrigues FA (2007) Potassium and plant disease. In: Danthoff LE, Elmer WH, Huber DM (eds) Mineral nutrition and plant disease. The American Phytopathological Society, St Paul, pp 57-78

Seasol International. (2015). Biostimulants in farming. Seasol International, Bayswater. http://www.commercial.seasol.com.au/. Accessed 1 Mar 2015

Siemens J, Keller I, Sarx J, Kunz S, Schuller A, Nagel W, Schmülling T, Parniske M, Ludwig-Müller J (2006) Transcriptome analysis of Arabidopsis clubroots indicate a key role for cytokinins in disease development. Mol Plant Microbe Interact 19:480-494

Stewart KL (2008) Conventional and novel treatments for control of clubroot disease of brassicas. PhD Thesis, The University of Edinburgh

Subramanian S, Sangha JS, Gray BA, Singh RP, Hiltz D, Critchley AT, Prithiviraj B (2011) Extracts of the marine brown macroalga, Ascophyllum nodosum, induce jasmonic acid dependent systemic resistance in Arabidopsis thaliana against Pseudomonas syringae pv. tomato DC3000 and Sclerotinia sclerotiorum. Eur J Plant Path 131:237-248

Tay SAB, MacLeod JK, Palni LMS, Letham DS (1985) Detection of cytokinins in a seaweed extract. Phytochem 24:2611-2614

Tay SAB, Palni LMS, MacLeod JK (1987) Identification of cytokinin glucosides in a seaweed extract. J Plant Growth Regul 5:133-138

Verkleij FN (1992) Seaweed extracts in agriculture and horticulture: a review. Biol Agric Hortic 8:309-324

Webster MA, Dixon GR (1991) Boron, pH, and inoculum concentration as factors limiting root hair colonisation by Plasmodiophora brassicae Wor. Mycol Res 95:74-79 